\title{
EFEK BISING MESIN ELEKTRONIKA TERHADAP GANGGUAN FUNGSI PENDENGARAN PADA PEKERJA DI KECAMATAN SARIO KOTA MANADO, SULAWESI UTARA
}

\author{
${ }^{1}$ Hardini Tjan \\ ${ }^{2}$ Fransiska Lintong \\ ${ }^{2}$ Wenny Supit \\ ${ }^{1}$ Kandidat Skripsi Fakultas Kedokteran Universitas Sam Ratulangi Manado \\ ${ }^{2}$ Bagian Fisika Fakultas Kedokteran Universitas Sam Ratulangi Manado \\ Email: tjan_diny@yahoo.com
}

\begin{abstract}
Noise induced hearing loss is caused by noise loud in the long period and a noisy work environment. Noisy work environment is a major problem in occupational health in various countries. The relationship between excessive noise exposure and hearing loss has been recognised since ancient times. Early epidemiological studies of noise induced hearing loss explored the damage risk relationship between occupational noise exposure level and the degree of hearing loss. The purpose of this study is to determine effect of engine noise electronics to auditory disfunction. The research methodeology used is an analytical method with a cross sectional approach. Samples were of 20 person taken from workers at the playground timezone and amazone. Data were obtained through questionnaires and examination of hearing function with the audiometri. Data were analyzed by using the Statistical Product and Service Solutions program (SPSS) and using the Fisher Exact test. Conclusion: The results showed that : There is a $75 \%$ hearing loss in all worker. The results of bivariate analysis showed there is no significant association between the hearing loss with the intensity level of noise $(\mathrm{p}=0,032)$. The most common hearing loss is sensorineural deafness which generally occours in both ear. From the result of this study it can be concluded that the workers who work in a place that has the high intensity noise have greater risk of suffening from hearing loss.
\end{abstract}

Keywords: Timezone and Amazone Workers, Noisy, Hearing.

\begin{abstract}
Abstrak: Gangguan pendengaran akibat bising ialah gangguan pendengaran yang disebabkan akibat terpajan oleh bising yang cukup keras dalam jangka waktu yang cukup lama dan biasanya disebabkan oleh bising di lingkungan kerja. Bising lingkungan kerja merupakan masalah utama pada kesehatan kerja di berbagai negara. Hubungan antara paparan bising yang berlebihan dan kehilangan pendengaran telah dikenal sejak zaman kuno. Awal studi epidemiologi, gangguan pendengaran yang disebabkan oleh bising mengeksplorasi adanya hubungan atau faktor resiko antara pekerjaan, paparan tingkat kebisingan dan derajat gangguan pendengaran. Tujuan penelitian ini untuk mengetahui efek bising mesin elektronika terhadap gangguan fungsi pendengaran. Metode penelitian yang digunakan yaitu metode analitik dengan menggunakan rancangan cross sectional study. Sampel berjumlah 20 orang yang diambil dari pekerja di tempat bermain timezone dan amazone. Data diperoleh melalui kuisioner dan pemeriksaan fungsi pendengaran dengan menggunakan Audiometri. Data dianalisis dengan menggunakan Statistical Program Product and Service Solution (SPSS) dan menggunakan uji Fisher Exact. Simpulan: Hasil penelitian menunjukkan bahwa : Terdapat gangguan pendengaran sebesar $75 \%$ pada seluruh pekerja. Hasil analisis bivariat menunjukan ada hubungan yang bermakna antara gangguan pendengaran dengan tingkat intensitas bising $(\mathrm{p}=0,032)$. Gangguan pendengaran yang paling banyak diderita oleh pekerja adalah tuli
\end{abstract}


sensorineural (persepsi) yang umumnya terjadi pada kedua telinga. Dari hasil penelitian ini dapat disimpulkan bahwa pekerja yang bekerja pada intensitas bising yang tinggi memiliki resiko lebih besar menderita gangguan pendengaran.

Kata Kunci: Pekerja Timezone \& Amazone, Bising, Pendengaran

Bising didefinisikan sebagai bunyi yang tidak dikehendaki yang merupakan aktivitas alam (bicara, pidato) dan buatan manusia (bunyi mesin). ${ }^{1}$ Dalam rangka perlindungan kesehatan tenaga kerja kebisingan diartikan sebagai semua suara/bunyi yang tidak dikehendaki yang bersumber dari alat proses produksi atau alat-alat kerja yang pada tingkat tertentu dapat menimbulkan gangguan pendengaran. ${ }^{2,3}$

Awal studi epidemiologi gangguan pendengaran yang disebabkan oleh bising mengeksplorasi adanya hubungan atau faktor risiko antara pekerjaan, paparan tingkat kebisingan dan derajat gangguan pendengaran. ${ }^{4}$ Di Amerika Serikat sekitar 10 juta orang dewasa dan 5,2 juta anak sudah menderita gangguan pendengaran akibat bising dan 30 juta lebih lainnya dapat terkena dampak bising yang berbahaya setiap harinya. ${ }^{5}$

Survey terakhir dari Multi Center Study (MCS) juga menyebutkan bahwa Indonesia merupakan salah satu dari empat negara di Asia Tenggara dengan prevalensi gangguan pendengaran cukup tinggi, yakni 4,6\% sementara tiga negara lainnya yakni Sri Lanka (8,8 \%), Myanmar (8,4 \%), dan India $(6,3 \%)$. Menurut studi tersebut prevalensi 4,6\% sudah bisa menjadi referensi bahwa gangguan pendengaran memiliki andil besar dalam menimbulkan masalah sosial di tengah masyarakat. ${ }^{6}$

Menurut Komnas PGPKT intensitas bising yang masih aman untuk telinga kita adalah sampai $80 \mathrm{~dB}$ dengan lamanya pajanan selama 24 jam tanpa penggunaan proteksi telinga seperti iPod, MP3, Timezone. ${ }^{7}$ Paparan suara bising yang keras atau terus menerus dapat mengganggu fungsi telinga dalam hal pendengaran. Bila paparan bising melampaui ambang batas yang diperkenankan berlangsung dalam waktu yang lama dan tanpa disadari dapat menyebabkan ketulian. ${ }^{7,8}$ Ketulian akan meng- akibatkan menurunnya kualitas hidup ( $Q u$ ality of Life) seseorang dan berdampak terhadap kualitas sumber daya manusia. ${ }^{7,9,10}$

Suara bising tidak disukai orang yang mendengarkan dan mempengaruhi suara yang ingin didengarakan (Olishifski, 1988). ${ }^{11}$ Bising merupakan bunyi yang ditimbulkan oleh gelombang suara dengan intensitas dan frekuensi yang tidak menentu. $^{12}$

Telinga adalah bagian yang didesain secara cerdas yang mengubah geombang bunyi mekanis di udara menjadi denyutdenyut elektris pada syaraf pendengaran. ${ }^{13}$ Telinga terdiri dari tiga bagian yaitu: telinga luar, telinga tengah, dan telinga dalam. Suara yang keras dapat menyebabkan otot pada telinga untuk menarik sisi-sisi ossicle dan mengurangi intensitas suara yang mencapai telinga dalam. ${ }^{14,15,16}$

\section{METODE PENELITIAN}

Jenis Penelitian yang digunakan adalah analitik dengan rancangan cross sectional study. Waktu penelitian dilakukan bulan Desember 2011 - Januari 2012. Tempat penelitian dilaku-kan di tempat bermain Timezone Manado Town Square dan Amazone Megamall Kecamatan Sario Kota Manado, Sulawesi Utara. Populasi adalah semua pekerja di tempat bermain Timezone Manado Town Square dan Amazone Megamall Keca-matan Sario Kota Manado, Sulawesi Utara. Sampel penelitian diambil dengan meme-nuhi criteria inklusi diantaranya: berprofesi sebagai pekerja di tempat bermain Timezone Manado Town Square dan Amazone Megamall Kecamatan Sario Kota Manado, Sulawesi Utara; Sudah bekerja di tempat tersebut minimal satu tahun; Bersedia untuk diperiksa dan menandatangani informed consent. Variabel penelitian terdiri dari dua variabel diantaranya Variabel bebas (inde- 
pendent) yaitu bising mesin elektronika dan Variabel terikat (dependent) yaitu Fungsi Pendengaran.

Pengambilan data diperoleh dari kuisioner yaitu tanya jawab langsung dengan responden terpilih dengan menggunakan daftar pertanyaan terstruktur. Data juga diperoleh melalui pengukuran tingkat kebisingan dengan menggunakan alat sound level meter. Selanjutnya data diperoleh melalui pemeriksaan fungsi pendengaran dengan menggunakan alat audiometri. Analisis data dilakukan dengan uji fisher exact yang menggunakan program SPSS.

\section{HASIL}

Lokasi penelitian dilakukan di dua tempat karena jumlah sampel di satu tempat tidak memenuhi standar penelitian. Pengukuran kebisingan diukur sesuai dengan bagian kerja yaitu pertama bagian area bermain yang berjumlah 16 orang dengan tingkat kebisingan yang didapatkan rata-rata $\pm 97 \mathrm{~dB}$ (Timezone Mantos) dan \pm $93 \mathrm{~dB}$ (Amazone Megamall). Bagian kedua adalah bagian office yang berjumlah empat orang dengan tingkat kebisingan rata-rata \pm $82 \mathrm{~dB}$ (Timezone Mantos) dan $\pm 80 \mathrm{Db}$ (Amazone Megamall).

Berdasarkan analisis univariat karakteristik responden dalam penelitian ini meliputi umur, lama bekerja, durasi kerja, tingkat kebisingan, derajat gangguan pendengaran, gangguan pendengaran kiri, gangguan pendengaran kanan. Untuk memperoleh gambaran distribusi menurut karakteristik responden dapat dilihat pada tabel berikut:

Tabel 1. Distribusi responden menurut umur.

\begin{tabular}{lcc}
\hline Kelompok & n & Persen \\
Umur & 7 & 35,0 \\
$17-20$ & 10 & 50,0 \\
$21-30$ & 3 & 15,0 \\
$31-40$ & 20 & 100,0 \\
\hline Total &
\end{tabular}

Tabel satu menunjukkan bahwa responden yang masuk dalam kelompok umur
21-30 tahun lebih banyak yaitu berjumlah 10 orang, dengan presentase $50 \%$, dibandingkan kelompok umur 17 - 20 tahun, dan 31 - 40 tahun.

Tabel 2. Distribusi responden menurut lama kerja.

\begin{tabular}{lcc}
\hline Lama Kerja & N & Persen \\
\hline$<5$ tahun & 15 & 75,0 \\
$6-10$ tahun & 3 & 15,0 \\
$>10$ tahun & 2 & 10,0 \\
\hline Total & 20 & 100,0 \\
\hline
\end{tabular}

Berdasarkan data menurut lama bekerja sebagai pekerja di timezone dan amazone, Pekerja yang termasuk dalam kelompok kurang dari lima tahun adalah yang paling banyak yaitu sebanyak 15 orang dengan presentase $75 \%$, dibandingkan dengan kelompok 6 - 10 tahun dan $>10$ tahun.

Tabel 3. Distribusi responden menurut durasi kerja.

\begin{tabular}{lcc}
\hline Durasi Kerja & n & Percent \\
\hline 8 jam & 13 & 65,0 \\
7 jam & 7 & 35,0 \\
\hline Total & 20 & 100,0 \\
\hline
\end{tabular}

Dari hasil penelitian yang telah dilakukan didapatkan hasil durasi kerja dalam sehari terbanyak adalah para pekerja yang memiliki durasi bekerja selama delapan jam yaitu dengan jumlah 13 orang (65\%).

Tabel 4. Distribusi responden menurut tingkat bising.

\begin{tabular}{lcc}
\hline Tingkat Bising & n & Percent \\
\hline$\geq 85 \mathrm{~dB}$ & 16 & 80,0 \\
$<85 \mathrm{~dB}$ & 4 & 20,0 \\
\hline Total & 20 & 100,0 \\
\hline
\end{tabular}

Dari hasil pengukuran yang telah dilakukan menggunakan alat Sound Level Meter didapatkan hasil terbanyak adalah para pekerja yang bekerja pada tingkat bising $\geq 85 \mathrm{~dB}$ yaitu dengan jumlah 16 orang $(80 \%)$. Pekerja yang bekerja pada tingkat bising $<85 \mathrm{~dB}$ berjumlah empat orang dengan presentase $20 \%$. 
Tabel 5. Distribusi responden menurut derajat ketulian.

\begin{tabular}{lcc}
\hline \multicolumn{1}{c}{ Hasil } & n & Persen \\
\hline Normal & 5 & 25,0 \\
Tuli Ringan & 12 & 60,0 \\
Tuli Sedang & 2 & 10,0 \\
Tuli Berat & 1 & 5,0 \\
\hline Total & 20 & 100,0 \\
\hline
\end{tabular}

Setelah dilakukan pemeriksaan fungsi pendengaran dengan menggunakan Audiometri terdapat lima orang yang normal ,12 orang menderita tuli ringan, dua orang menderita tuli sedang, dan satu orang menderita tuli berat.

Tabel 6. Distribusi responden menurut gangguan pendengaran.

\begin{tabular}{lcc}
\hline \multicolumn{1}{c}{ Hasil } & n & Persen \\
\hline Normal (kiri,kanan) & 5 & 25,0 \\
Tuli Kiri & 5 & 25,0 \\
Tuli Kanan & 3 & 15,0 \\
Tuli Kiri + Kanan & 7 & 35,0 \\
\hline Total & 20 & 100,0 \\
\hline
\end{tabular}

Tabel enam menunjukkan setelah dilakukan pemeriksaan fungsi pendengaran terdapat lima orang yang normal ( kiri + kanan ), lima orang menderita tuli telinga kiri, dan tiga orang menderita tuli telinga kanan, dan tujuh orang menderita tuli telinga kiri dan kanan.

Berdasarkan analisis bivariat terdapat tiga sel yang memiliki harapan kurang dari lima dan jumlah sampel tidak cukup dari 40 sampel, sehingga tidak memenuhi kriteria Uji Chi-Square maka dilakukan uji alternatif lain yaitu Uji Fisher dengan nilai sampel kurang dari 40 atau 20 - 40 sampel dengan nilai harapan kurang dari lima. Nilai Uji Fisher yang didapatkan yaitu $p=$ $0,032(\mathrm{p}=<0,05)$.

\section{BAHASAN}

Dari hasil penelitian dengan menggunakan alat audiometri didapatkan lima pekerja tidak mengalami gangguan pendengaran $(25 \%)$ dan 15 orang pekerja mengalami gangguan pendengaran $(75 \%)$ dengan berbagai tingkat ketulian, dimana didapatkan hasil berupa peningkatan ambang pendengaran diatas $25 \mathrm{~dB}$. Tingkat ketulian ditentukan dengan menggunakan kriteria ISO (International Standard Organitation) yang normalnya adalah $0-25 \mathrm{~dB}$.

Berdasarkan data menurut lama bekerja sebagai pekerja di dua tempat penelitian, pekerja yang termasuk dalam kelompok kurang dari lima tahun adalah yang paling banyak yaitu sebanyak 15 orang dengan presentase $75 \%$. Dari hasil penelitian yang telah dilakukan juga didapatkan hasil durasi kerja dalam sehari terbanyak adalah para pekerja yang memiliki durasi bekerja selama delapan jam yaitu dengan jumlah 13 orang $(65 \%)$.

Berdasarkan gangguan pendengaran yang paling banyak dialami pekerja pada penelitian ini adalah tuli kedua telinga ( kiri + kanan ) sebanyak tujuh orang pekerja sedangkan tuli telinga kiri lima pekerja dan yang tuli telinga kanan terdapat pada tiga orang pekerja. Hal ini ini sesuai dengan tinjauan pustaka yang menyebutkan bahwa sifat ketulian dari gangguan pendengaran akibat bising di tempat kerja pada umumnya pada kedua telinga dan merupakan tuli sensorineural (persepsi). ${ }^{16}$

Gangguan pendengaran akibat bising (noise induced hearing loss) ialah gangguan yang disebabkan akibat terpajan oleh bising yang cukup keras dalam jangka waktu yang cukup lama, dan biasanya diakibatkan oleh bising dilingkungan kerja. Sifat ketuliannya adalah tuli sensorineural (persepsi) dan pada umumnya pada kedua telinga. ${ }^{16}$

Setelah dilakukan pemeriksaan fungsi pendengaran dengan menggunakan audiometri terdapat lima orang yang normal ,12 orang menderita tuli ringan, dua orang menderita tuli sedang, dan satu orang menderita tuli berat. Nilai ambang batas kebisingan ditempat kerja yang menjadi tempat penelitian ini, telah melampaui batas yang telah ditetapkan di Indonesia yang seharusnya adalah $85 \mathrm{dBA}$ untuk durasi kerja delapan jam perhari. ${ }^{12,16}$ Secara umum bising yang intensitasnya 85 desibel (dB) atau lebih, dapat mengakibatkan kerusakan pada reseptor pendengaran Corti pada ba- 
gian telinga dalam. Yang sering mengalami kerusakan adalah alat Corti untuk reseptor bunyi yang berfrekwensi $3000 \mathrm{~Hz}$ sampai dengan $6000 \mathrm{~Hz}$ dan yang terberat kerusakan alat Corti untuk reseptor bunyi yang berfrekwensi $4000 \mathrm{~Hz}^{16}$

Penelitian sebelumnya yang pernah dilakukan antara lain, pada pekerja pabrik manufaktur bahan perekat di Taiwan. Penelitian ini dilakukan pada 116 pekerja yakni 58 pekerja di pabrik dan 58 lainnya di bagian administrasi. Kedua tempat ini mempunyai tingkat intensitas bising yang berbeda yaitu $90 \mathrm{~dB}$ di pabrik dan $<70 \mathrm{~dB}$ di bagian administrasi. Dari penelitian ini didapatkan hasil pekerja yang mengalami gangguan pendengaran adalah sebesar $67,2 \%$ dari 116 pekerja. $^{17}$

Adapun penelitian yang dilakukan pada pekerja pabrik pipa baja di Timur Arab Saudi. Penelitian dilakukan pada 368 pekerja yakni 269 pekerja di pabrik dan 99 lainnya di bagian administrasi. Kedua tempat ini mempunyai tingkat intensitas bising yang berbeda yaitu $95,4 \mathrm{~dB}$ di pabrik dan $84,8 \mathrm{~dB}$ di bagian administrasi. Dari penelitian ini didapatkan hasil pekerja yang mengalami gangguan pendengaran adalah sebesar $75 \%$ dari 269 pekerja. ${ }^{18}$

Penelitian selanjutnya juga dilakukan pada pekerja pabrik baja di Sidoarjo Jawa Timur. Penelitian ini dilakukan pada 50 pekerja yakni 25 pekerja di pabrik dan 25 lainnya di bagian administrasi. Kedua tempat ini mempunyai tingkat intensitas bising yang berbeda yaitu $102 \mathrm{~dB}$ di pabrik dan $60,4 \mathrm{~dB}$ di bagian administrasi. Dari penelitian ini didapatkan hasil pekerja yang mengalami gangguan pendengaran adalah sebesar $84 \%$ dari 50 pekerja. ${ }^{19}$

Beberapa penelitian tersebut memperoleh kesimpulan yang sama yaitu pekerja yang bekerja pada intensitas bising tinggi memiliki resiko lebih besar menderita gangguan pendengaran dibandingkan dengan pekerja yang bekerja pada intensitas bising rendah.

Hasil penelitian yang telah disebutkan diatas kemudian dibuktikan menggunakan uji chi square dan berdasarkan hasil penelitian ditemukan jumlah sampel $<40$ dan tiga sel memiliki nilai kurang dari lima sehingga tidak memenuhi syarat uji chi square, maka dilakukan uji alternatif lain yaitu uji fisher exact. Data yang diperoleh melalui uji fisher exact menunjukkan nilai $\mathrm{p}=0,032 \quad(\mathrm{p}<0,05)$ yang berarti data ini signifikan. Hal ini membuktikan bahwa pekerja yang bekerja pada intensitas bising tinggi ( $\geq 85 \mathrm{~dB})$ memiliki resiko lebih besar menderita gangguan pendengaran, dibandingkan dengan pekerja yang bekerja pada intensitas bising rendah $(\leq 85 \mathrm{~dB})$.

\section{SIMPULAN DAN SARAN}

Terdapat gangguan pendengaran pada pekerja. Gangguan pendengaran yang paling banyak diderita oleh para pekerja ini adalah tuli sensorineural (persepsi) yang pada umumnya terjadi pada kedua telinga. Dari hasil analisis bivariat data yang diperoleh melalui uji fisher exact menunjukkan nilai $\mathrm{p}=0,032(\mathrm{p}<0,05)$ yang berarti data ini signifikan. Hal ini membuktikan bahwa adanya hubungan antara efek bising terhadap gangguan fungsi pendengaran.

Bagi pekerja agar dapat mengetahui bising terhadap gangguan fungsi pendengaran dengan menggunakan alat pelindung telinga (ear plugs) selama melakukan pekerjaan dan dapat mengurangi jam kerja sehingga resiko gangguan pendengaran dapat dicegah.

\section{DAFTAR PUSTAKA}

1. Gabriel JF. Fisika Kedokteran. Jakarta: EGC, 1996; p.82-95.

2. Suma'mur PK. Higiene Perusahaan dan Kesehatan Kerja (HIPERKES). Jakarta: Sagung Seto, 2009; 116-32.

3. Yuwono SR, Amin M. Bidang Penelitian dan Pengembangan RSU Dr Soetomo Surabaya. Buletin Penelitian RSU Dr Soetomo. 2007;9(4):191-5.

4. Rabinowitz PM, Galusha D, Ernst CD, Slade MD, Cullen MR. Do ambient noise exposure levels predict hearing loss in a modern industrial cohort. Occup Environ Med. 2007; 64: 53-9.

5. Seidman MD, Standring RT. Noise and quality of life. International Journal of 
Environmental Research and Public Health. 2010;7:3730-8.

6. Ali I. Mengatasi Gangguan pada Telinga dengan Tanaman Obat. Jakarta: Agromedia Pustaka, 2006; p.1-14.

7. Husni TR. Waspadai Bising [homepage on the Internet]. Nodate [cited 2011 August 24]. Available from: URL: http://www.ccde.or.id/index.php?option=c om content\&view $=$ article\&id $=458$ : waspa dai bising $\&$ catid $=21$ : sehati\& Itemid $=28$.

8. Kirchner D, Evenson E, Dobie RA, Rabinowitz P, Crawford J, Kopke R, et.al. Occupational noise-induced hearing loss. JOEM. 2012;54:106-8.

9. Arifiani N, Roestam AW. Cermin Dunia Kedokteran 144 THT. Jakarta: Cempaka Putih; 2004: 24-33.

10. Hani AR. Teori dan Aplikasi Fisika Kesehatan. Yokyakarta: Nuha Medika, 2010; p.41-53.

11. Jeyaratnam J. Buku Ajar Praktik Kedokteran Kerja. Jakarta: EGC, 2009; p.237-42.

12. Harrianto R. Buku Ajar Kesehatan Kerja. Jakarta: EGC, 2009; p.129-47.
13. Cameron JR, Skofronick JG, Grant RM. Fisika Tubuh Manusia. Jakarta: EGC, 2006; p.304-19.

14. Alberti PW. The Anatomy and Physiologi of The Ear and Hearing. Singapore: Department of Otolaryngology, 1970; p.53-62.

15. Herawati S, Rukmini S. Buku Ajar Ilmu Penyakit Telinga Hidung Tenggorok. Jakarta: EGC, 2003; p.1-8.

16. Soepardi EA, Iskandar N, Bashiruddin J, Restuti RD. Buku Ajar Ilmu Kesehatan Telinga Hidung Tenggorok Kepala dan Leher. Jakarta: FKUI, 2007; p.10-52.

17. Chang SJ, Chen CJ, Lien CH, Sung FC. Hearing loss in workers exposed to toluene and noise. Environmental Health Perspectives. 2006;114:1283-86.

18. Ahmed HO, Dennis JH, Badrans O, Ismail M, Ballal SG, Ashoor A, et.al. Occupational noise exposure and hearing loss of workers in two plants in Eastern Saudi Arabia. Ann Occup Hyg. 2001;45:371-80.

19. Harmadji S, Kabullah H. Noise induced hearing loss in steel factory workers. Folia Medica Indonesiana. 2004;40:171-7. 